\title{
El perquè de la reproducció
}

Teresa Torns

Pilar Carrasquer

Universitat Autònoma de Barcelona. D epartament de Sociologia

08193 Bellaterra (Barcelona). Spain

\section{Resum}

L'objectiu del text és contribuir al debat sobre el perquè, el què i el com de la recerca sociològica al voltant d'una temàtica (el treball) i d'una perspectiva (les desigualtats socials que el presideixen). La contribució de les autores desenvolupa seguint una trajectòria temporal que permet veure com s'ha anat construint una determinada manera d'analitzar tot el treball existent i tots els col·lectius que hi són implicats. Així es mostra, en primer Iloc, l'inici de la preocupació pel lema que encapçala aquestes pàgines, el perquè de la reproducció. En segon lloc, es clarifica el plantejament de fons que orienta aquesta aproximació al treball i, en tercer lloc, es detalla el contingut d'algunes de les recerques realitzades sota el punt de vista proposat. Finalment, s'afegeixen unes darreres reflexions sobre la validesa i les dificultats de l'enfocament plantejat. Per tal de no convertir l'exposició en un aparador del gènere disponible, cal recordar que aquestes reflexions s'insereixen en el context de discussió sobre aquesta temàtica iniciat ara fa poc més de quinze anys, per les que escriuen aquest text, a les Primeres J ornades de Sociologia Catalana, celebrades el maig de 1981.

\section{Abstract}

The objective of this text is to make a contribution to the debate about why, what and how is the sociological research around one subject (work) and a specific theoretical pers pective (social inequalities that surround it). This contribution wants to follow a temporary sequence oriented to show the way the authors have analysed the whole work that exists in our society and all the collectives affected. That means to explain, first of all, the beginning of the reasons implied in the title of these pages, «why about reproduction». After that, to clarify the framework of the theoretical approach to this concept of work and to detail the results of some research done using this perspective. The text point out also some arguments around the difficulties of this point of view. And finally, the authors remember that they only want to participate on a debate that they begun fifteen years before in 1981 at the Primeres Jornades de Sociologia Catalana unless they know that gender perspective would be presented in a more wide vision.

\section{Sumari}

El punt de partida

Proposta de revisió conceptual:

del treball als treballs i del sexe al génere
Alguns exemples de l'aplicació d'aquests plantejaments

Conclusions

Bibliografia 


\section{El punt de partida ${ }^{1}$}

El nostre interès per la temàtica proposada s'origina ara fa uns vint anys, al si d'un col'lectiu no acadèmic on es realitzaven estudis sobre les relacions laborals, el treball i, en general, l'activitat laboral. En aquest context, la nostra preocupació inicial se centra en el treball (de moment, assimilat al que avui anomenem ocupació) i, en concret, en la situació «específica» (avui en diem desigual) d'un col·lectiu («a dona») en relació amb un altre («'home») que mostren les xifres oficials del'activitat laboral. Per tant, el punt de partida és el treball, no la dona, el feminisme o el gènere (concepte d'introducció molt més recent a C atalunya i a Espanya). I ens hi apropem des d'una perspectiva «crítica», d'arrels marxistes heterodoxes.

En aquell moment, les explicacions més habituals en relació amb l'«especificitat femenina al mercat de treball», provenen de la tradició que els experts en mercat de treball qualifiquen de neoclàssica (capital humà...) i del'esmentada tradició marxista o crítica, potser menys estesa en el món acadèmic que l'anterior, però «socialment present» a l'època. Els conceptes de cost d'oportunitats, per un costat, i de divisió sexual del treball i d'exèrcit de reserva, per un altre, suposen el principal bagatge teòric per tal d'explicar la disparitat de situacions en relació amb el treball observades segons el sexe. Aquest tipus d'explicació ens sembla insatisfactori. Al nostre parer, I'origen de la disparitat no rau exclusivament en la lògica de mercat, sinó justament «fora» del mercat de treball: en la «funció reproductora» que les dones tenen socialment encomanada, seguint la terminologia usada per Benería (1981), entenent que aquesta funció reproductora suposa per les dones una càrrega de treball socialment invisible que incideix tant en la possible participació femenina en l'activitat productiva (limitant-la, subordinant-la...) com en la masculina (facilitant-la). La proposta s'adreça, per tant, a la revisió del mateix concepte de treball, ampliant el seu contingut de manera que inclogui tant les activitats orientades a la producció de béns i serveis que «passen pel mercat», independentment de la fórmula contractual que adoptin, com aquelles orientades a la reproducció biològica, social i ideològica de la força de treball. En aquest sentit, parlem de treball produc tiu i de treball reproductiu, respectivament ${ }^{2}$.

La revisió del concepte de treball no es limita a una ampliació del nombre i del tipus d'activitats que anomenem com a tal. Suposa una ruptura conceptual amb aquelles perspectives que centren la seva capacitat explicativa únicament en el mercat i/o en les relacions socials de producció. I fa emergir el treball de la reproducció com a nou objecte d'estudi d'alt interès per a la sociologia del treball, al mateix temps que defineix uns Iligams entre dos àmbits (el de la producció de mercaderies i el de la reproducció de les persones), que poden restar analíticament separats però que mantenen la capacitat explicativa del treball com a eix primordial de desigualtat. Vegem-ho.

1. Vegi's Carrasquer, Estivill, Tomás i Torns (1985).

2. Aquest és el plantejament proposat a Torns i Carrasquer (1983 i 1987). 
2. Proposta de revisió conceptual: del treball als treballs i del sexe al gènere

La revisió de concepte de treball prové d'una doble insatisfacció. Per un costat, la que es deriva de les anàlisis interessades a explicar la «situació social de les dones», per usar una expressió molt popular durant una època i, per l'altre, la que sorgeix de les anàlisis interessades a explicar les pròpies transformacions en el treball productiu ${ }^{3}$, al mateix temps que des de tots dos punts de vista es fa palesa la necessitat de millorar les eines de mesura d'allò que s'entén per treball ${ }^{4}$.

Ara bé, per ubicar l'origen del concepte de treball de la reproducció cal fer esment al debat feminisme-marxisme de finals dels anys setanta, en relació amb el treball domèstic. Aquest debat sorgeix arran de la discussió sobre les característiques d'aquest treball i la seva relació amb el procés d'acumulació capitalista. D it d'una altra manera, el debat es planteja al voltant dels continguts i de les relacions socials que envolten el treball domètic, d'una banda, i la relació entre aquest treball i la resta d'institucions i/o sistemes socials, d'una al tra. Tot plegat, amb l'objectiu d'explicar la divisió sexual del treball observable, si més no, als països capitalistes. Simplificadament, podríem dir que el debat es resol amb un cert consens en relació amb la consideració que el treball domès tic és distint del treball productiu, ja que el primer es dóna sota unes relacions socials que tenen el seu origen en la institució familiar, mentre que el segon es desenvolupa sota unes relacions socials presidides per la desigual venda de força de treball a canvi d'un salari. La principal divergència es planteja en mirar de respondre per què unes persones tendeixen a estar més presents en un tipus de treball que d'altres. En aquest cas, la qüestió de fons que es planteja és la de la relació entre el tipus de producció capitalista i l'existència o no d'altres sistemes, institucions i/o processos socials que generen desigual tat social en termes de sexe-gènere, i no nomès de clase. És a dir, capitalisme versus patriarcat, fonamentalment ${ }^{5}$.

En part de forma paral-lela i en part fruit d'aquest debat, també el concepte de «dona» és subjecte de revisió. Es «desnaturalitza» la idea de dona, refermant una cosa que avui pot semblar òbvia, com és la construcció socio-

3. En aquest darrer cas, pensi's, per exemple, en Pahl i la seva proposta del concepte de «formes de treball» $(1983,1986,1990)$.

4. L'esforç per fer visible tant l'aportació femenina al conjunt de l'activitat (mercantil i no mercantil) com la seva presència en altres àmbits socials és present a nombroses publicacions a partir demitjans dels anys setantes. Fins i tot, organismes oficials com l'O N U recomanen la millora de les estadístiques oficials de manera que permetin copsar aquesta aportació i aquesta presència. En aquesta línia, cal recordar el Seminari sobre Indicadors Socials, impulsat pel Seminari d'Estudis de la D ona de la UAB, celebrat I'any 1985.

5. Per a una bona síntesi d'aquest debat i de les temàtiques i objectes d'estudi que en cada cas se'n deriven, es pot consultar el capítol introductori de Borderías, Carrasco i Alemany (1994). Així mateix, a la bibliografia que tanca aquestes pàgines s'inclou una selecció de les autores i textos d'interès sobre la qüestió. 
històrica d'allò associat al fet de ser dona o home. També es qüestiona la capacitat explicativa que pot tenir la variable sexe i es parla de la dimensió de gène re, seguint la tradició anglosaxona que sembla acabar per imposar-se, 0 de relacions socials de sexe, segons la tradició francesa avui menys present.

Aquest marc de discussió i de revisió conceptual constitueix el nostre punt de partida per a la definició del treball de la reproducció que hem anat utilitzant (i polint) i per a la construcció d'un model d'anàlisi del treball que anomenem model de producció/reproducció, seguint la terminologia del grup de Cambridge U na definició de treball que podem resumir amb la citació següent ${ }^{6}$.

[... ] el treball és el factor que consolida la desigualtat social femenina. U na desigual tat que actua de manera interdependent a d'altres (les derivades de la classe social i del'ètnia, si és el cas) i quete les seves arrels en el procés de socialització. Tal com expliquen les especialistes en educació, aquest procés converteix les femelles en dones i els mascles en homes, fixant l'origen d'una desigual tat per raó de gènere que condicionarà tant la materialitat de la vida com les representacions simbòliques que s'edifiquin al seu damunt.

Aquest procés socialitzador reverteix en l'àmbit del treball de la manera següent: les dones són educades per realitzar central ment un treball no reconegut com a tal, ni socialment ni econòmicament, el treball de cura de la llar i de la família (treball de la reproducció), mentre que els homes podran construir el seu projectecentral de vida sobre el treball de la producció. Aquest sí que és reconegut socialment, econòmicament i acadèmicament com a treball [... ] Q uan les dones aconsegueixen desenvolupar aquest segon tipus de feina han d'optar entre la «doble presència» o la «masculinització».

La divisió de tasques a la qual condueix aquest procés socialitzador produeix, en les actuals societats industrialitzades, una divisió sexual del treball que té el seu escenari privilegiat a la llar i a la família. Al mateix temps que influeix en les possi bilitats de participació femenina en l'activitat productiva, en no reconèi xer la incidència de les càrregues reproductives que solament les dones tenen atribuïdes. L'existència d'aquesta divisió no solament dibuixa diferències entre homes i dones, sinó que també configura desigualtats. Perquè a la societat patriarcal, que actua com a marc general de referència per a tal situació, solament es prestigia allò productiu-masculí, de tal manera que les dones o trebaIlen de manera invisible 0 en situació de manifesta desigualtat [... ]

Aquestes desigualtats tenen un caràcter estructural i són absolutament necessàries per mantenir l'actual situació de l'organització productiva. D 'aquí la necessitat d'estudiar-lesi de fer-les evidents per tal de posar de manifest la seva existència. La perspectiva teòrica que permet més bé la seva anàlisi és la que combina el treball de la producció amb el de la reproducció, perquè solament d'aquesta manera es poden analitzar els dos treballs i mostrar la importància de la tasca de la reproducció en el mercat de treball [... ] [finalment, pensem que] solament una òptica teòrica no productivista permet l'anàlisi dels treballs de

6. Torns i Carrasquer, El trabajo como consolidación de la desigualdad, ponència presentada al IV Congreso de Sociología, M adrid, setembre de 1992. 
les dones (i dels homes) i de les desigualtats de gènere que les acompanyen. U na necessitat teòrica que solament aconsegueix el seu objectiu si a més hom és capaç, en el moment de la mesura, de trencar amb els models habituals, tan sols acostumats a comptabilitzar les absències femenines en relació amb les presències masculines [... ]

\section{Alguns exemples de l'aplicació d'aquests plantejaments}

El contingut de les recerques realitzades fins ara mostra aquest doble esforç: per un costat, l'esforç de revisió conceptual i de proposta d'un model d'anàlisi (o de conjunt d'hipòtesis més o menys estructurades) que ens permeti encarar l'estudi del treball d'una manera més satisfactòria per a nosaltres. Per l'altre, i en la mesura que això és possible en el context institucional en què ens movem, l'esforç d'aplicació de la proposta teòrica a l'anàlisi d'aquells aspectes que poden mostrar més bé les distintes i desiguals formes de plantejar-se i de ser al el tre ball entre homes i dones. Així, l'interès pel treball i les desigualtats de gènere $s^{\prime}$ ha traduït en un conjunt de recerques que comparteixen un mateix marc teòric de partida i que han estat desevolupades al si del Grup d'Estudis sobre la Vida Q uotidiana i el Treball (QUIT), des de la seva creació, I'any 1988.

A) Un primer grup d'investigacions tenen com a fil conductor comú I'estudi de la situació laboral de les dones, prioritzant aquells aspectes i/o temàtiques habitualment menys vistes, però que, al nostre parer, permeten visualitzar més bé les desigualtats de gènere. Cronològicament són les següents:

- L'estudi de l'absentismelaboral femení. L'absentisme ha estat un objected'estudi «maleït»: habitualment se'n destaquen els seus efectes penalitzadors pel conjunt de la mà d'obra i solament des d'una perspectiva crítica es mostra com rebuig al «treball» i/o expressió individual de conflicte. Per nosaltres l'absentisme constitueix un bon exemple de les desigualtats de gènere. Així, tot i assumint la darrera dimensió assenyalada, I'absentisme potencial de les dones només s'explica si tenim present la seva dimensió de cost social de reproducció de la força de treball, tal com proposàvem l'any 19817 . Uns deu anys més tard podem aplicar aquest punt de vista en una recerca sobre l'absentisme laboral en un col-lectiu de treballadores del Parc Tauli ${ }^{8}$. En aquest cas, acabem de perfilar el concepte d'absentisme, entenent-lo com a expressió dels límits de la «doble presencia» de les dones: els resultats mostren la bondat del plantejament, però també apunten cap a un dels aspectes sobre el qual després hem seguit aprofundint, com és el de la diver-

7. Torns i Carrasquer, Algunasnotas sobre e absentismo de la mujer trabajadora, comunicació presentada al I Congreso de Sociología, Saragossa, 1981, juntament amb L. Bassols.

8. Recerca realitzada l'any 1990 per T. Torns i P. C arrasquer, sota conveni de col·laboració entre la U AB i el CH PT. També hi participen J.A. N oguera i F.J. M iguel Q uesada. 
sitat de formes que pot adoptar la «doble presència»; dit d'un altra mane$\mathrm{ra}$, les desigualtats de gènere, tal com el seu nom indica, afecten tot el gènere femení, però això no vol dir que totes les dones siguin iguals, ja que les desigualtats de gènere solament són, tal com hem vist en l'apartat precedent, un dels eixos de desigualtat que cal considerar.

- L 'atur femení. Si establíssim una ràtio entre la importància quantitativa del fenomen i la quantitat d'esforços dedicats a explicar-lo, el resultat tendiria a mostrar que el problema és inexistent. D e fet, l'atur tant com problema social com sociològic ha estat majoritàriament definit bé de manera «neutre», bé com a qüestió que afecta distints col lectius, bàsicament segons l'edat. N o obstant això,, si alguna cosa caracteritza l'atur i especialment l'atur de Ilarga durada al nostre país és el seu impacte sobre les dones. Partir d'una anàlisi que combini el treball de la producció i el dela reproducció ens ha permès, en primer lloc, puntualitzar de què parlem quan parlem d'atur; en segon Iloc, ens ha permès qüestionar algunes de les explicacions més habituals en relació amb l'atur ( «les dones no volen treballar», no estan prou «qualificades» i/o no tenen la «qualificació adient», per posar-ne uns exemples). I, en tercer Iloc, des d'una vessant més aplicada, aquest punt de vista ens ha permès identificar distints col-lectius d'aturades, segons una tipologia construïda sota dimensions que perfilen diferents situacions de treball, la qual cosa afavoreix trencar amb el mite de l'homogeneïtat entre les mateixes dones ${ }^{9}$. D es d'aquesta mateixa tessitura, darrerament les nos tres reflexions sobre l'atur femení i la manca d'exclusió social derivada directament d'aquest tipus d'atur ens han portat a l'elaboració d'hipòtesis sobre I'existència d'una forta tolerància social (en l'accepció d'hipocresia) envers aquest atur femení (Torns, 1997).

- L'assetjament sexual ${ }^{10}$. L'any 1995, el D epartament de Treball de la G eneralitat de $C$ atalunya i I'Institut $C$ atalà de la $D$ ona varen encarregar-nos un estudi sobre l'assetjament sexual al món laboral. Les hipòtesis i la problemàtica sobre la qüestió (assumida principalment pels juristes) ens varen portar a mostrar la creixent importància d'un tema vell amb un nom nou que no fa sinó indicar l'existència de poder en les relacions laborals. Un poder assumit amb una certa morbositat per via de sexe quan hi ha una jerarquia laboral explícita, i un poder que és negat quan el rerefons patriar-

9. Torns i C arrasquer, recerca sobre l'atur de llarga durada al Vallès $O$ ccidental, real itzada l'any 1991 sota conveni de col·laboració entre la UAB i el Consell Comarcal del Vallés O ccidental, amb la participació de X. Rambla i J.A. N oguera. La tipologia d'aturades que vàrem elaborar va ser aplicada posteriorment a l'anàlisi de l'atur femení a Espanya, en una recerca finançada per I'Instituto de la M ujer i realitzada per les autores d'aquestes pàgines i A. Romero, entre 1993 i 1994 (vegi's Torns, Carrasquer i Romero, 1995).

10. Recerca dirigida per $T$. T orns i realitzada juntament amb A. R omero, V. Borràs, A. Recio i Laia Pallejà. 
cal és la via principal d'explicació. L'estudi de la segregació ocupacional del mercat laboral femení fet per Albert Recio i els grups de discussió realitzats entre treballadors i treballadores varen ser maneres de constatar la no consciència sobre aquesta desigualtat de gènere.

- La segregació ocupacional ${ }^{11}$. U na de les regularitats que es poden observar en la presència femenina al mercat de treball és la seva tendència a protagonitzar determinats tipus d'ocupacions i a ocupar els llocs més baixos de la jerarquia laboral. Un fenomen que es coneix amb el nom de segregació ocupacional horitzontal i vertical. L'aplicació del model de producció/reproducció ens ha permès abordar aquest fenomen tenint present els factors «aborals» i «extralaborals» que hi poden incidir i aquells elements simbòlics que configuren distintes maneres d'estar en el treball (productiu i reproductiu). L'estratègia de recerca utilitzada va fer possible contrastar les diferents i desiguals situacions de treball entre homes i dones, però també la diversitat existent entre el propi col·lectiu femení, o diferents models de «doble presència», com els vàrem anomenar.

B) Paral·lelament a l'anàlisi de la situació laboral deles dones, el nostre interès també s'ha orientat vers el propi treball de la reproducció. (M enys estudiat perquè no s'esmercen recursos per veure el que no és considerat com a necessari conèixer.)

- Treball i vida quotidiana ${ }^{12}$. A questa recerca ens va permetre refinar la definició de treball de la reproducció, fent-la operativa per a la seva anàlisi en un escenari privilegiat: el d'una mostra de llars família de l'À rea M etropolitana de Barcelona ${ }^{13}$. El nostre objectiu no era tant quantificar les activitats o mesurar el temps que les persones hi dediquen, com tipificar les activitats, analitzar les relacions socials i els col lectius que les protagonitzen. I això tant en relació amb el propi treball de la reproducció com amb l'activitat laboral 0 amb el temps de lliure disposició personal. El treball de la reproducció el definim com aquell conjunt d'activitats orientades al manteniment i cura de la llar i de la família. En diem treball dela reproducció per distingir-lo del treball de la producció. I no usem el concepte de treball domèstic per recordar que les activitats que comprèn no es limiten a l'espai físic i simbòlic de la llar. M és detalladament, el treball de la reproducció consta de les dimensions bàsiques següents: la dimensió d'automanuten-

11. Recerca dirigida per P. Carrasquer i realitzada juntament amb R. Varella i J.A. N oguera, sota conveni de col·laboració entre la UAB i la Federació de Banca i Estalvi de C C.OO. durant 1994 i 1995 (vegi's Carrasquer, N oguera i Varella, 1996).

12. Recerca sobre les tran formacions al treball i a la vida quotidiana, real itzada pel QUIT entre 1991 i 1995, amb finançament de la D G ICYT. Producte d'aquesta recerca és el núm. 55 de la revista Papers, monogràfic titulat justament «Treball i vida quotidiana».

13. Es va utilitzar la base de dades de l'Enquesta M etropolitana de Barcelona de l'any 1990. 
ció, la relativa a les tasques d'infraestructura de la llar, la d'atenció de les càrregues reproductores passades, presents i futures, la d'organització del conjunt del treball de la reproducció, la de les tasques de mediació i la corresponent a les tasques de representació conjugal. En el benentès que aquests continguts tenen sentit a les societats capital istes industrial itzades i que no tots són igual ment rellevants o pertinents en cada context, ni que la seva materialització afecta per igual totes les dones. L'anàlisi tant de la «materialitat» d'aquest treball com de les representacions simbòliques que I'envolten ens va permetre aprofundir en el significat que aquest treball té per les persones. U n coneixement que, a més, va contribuir a definir diferents ti pus de persones segons la seva ubicació a l'entrellat producció/reproducció. Així es parlava, per exemple, de centralitat productiva o reproductiva. Conceptes $\mathrm{i}$ tipus que hem aplicat posteriorment com a base d'altres anà lisis.

Final ment, cal dir que aquest esforç de revisió teòrica i conceptual ha estat «socialitzat» al si del grup on treballem habitualment, de manera que la seva petjada s'aprecia amb més o menys intensitat a la recerca que, en general, es fa al Q UIT. Especialment a la recerca bàsica que es porta a terme sota el paraiga de la D GICYT, com la que actualment ens ocupa sobre el repartiment del tre ball. En aquest sentit, tot i que les autores acostumem a investigar sobre qüestions que tenen les dones com a protagonistes principals, cal assenyalar que també s'ha procurat aplicar allò que suggeríem a l'inici, és a dir, que la possible bondat del plantejament no rau exclusivament en la seva capacitat per explicar el treball de les dones, sinó en el paper que tot el treball té en la vida quotidiana de les persones.

\section{Conclusions}

Per acabar, volem comentar que la proposta presentada és una proposta conceptual i metodològica oberta i, per tant, sempre en revisió. Ja comentàvem a l'inici, que, pel que fa al model que orienta les nostres recerques, de fet, preferim parlar d'un conjunt d'hipòtesis estructurades que no pas d'un model tancat. No obstant això, la seva aplicació està essent profitosa, perquè ens permet disposar d'un marc de referència prou ampli i coherent com per abordar l'anàlisi de tot el treball socialment necessari per a la supervivència i reproducció quotidiana de les persones, i les desigual tats que se'n deriven. El nostre repte resta obert, perquè la necessitat de millorar aquesta proposta inicial no respon només a demandes de tipus epistemològic.

Finalment, també cal dir que aquest tipus de proposta es troba en un terreny «ncòmode»: des del punt de vista dela disciplina(es) que s'ocupen del treball és difícil trencar la lògica que limita treball a ocupacio, tot i l'esforç d'aclariment conceptual que efectivament s'ha realitzat. En canvi, comparativament, s'ha produït una ràpida institucionalització de tot allò que té a veure amb la dona/les dones, el gènere, etc., especialment pel que fa a aquells plantejaments 
que incideixen en l'especificitat sociocultural de les dones. N o obstant això, aquesta institucionalització moltes vegades es duu a terme en forma d'àrea feble 0 de calaix de sastre on s'insereixen prospostes amb gènere però sense que l'enfocament sobre les desigualtats sigui un requisit obligat. Tanmateix, no és la nostra opció, malgrat que sigui una opció possible.

\section{Bibliografia}

BALBO, L. (1979). «La doppia presenza». Inchiesta, núm. 32, M ilà.

BetTIO, F. (1988). The sexual division of Labour. O xford: Clarendon Press.

Borderías, C.; C arrasco, C.; Alem any, C. (1994). Las mujeres y el trabajo. Ruptu ras conceptuales $M$ adrid-Barcelona: Icària-FU HEM .

BOSERUP, E. (1977). Woman's role in economic development. Londres: Allen \& Unwin. CARRASQ UER, P.; ESTIVILL, J.; TOM ÁS, J.; T ORN S, T. (1985). «La sociologia del treball a C atalunya (1973-1980)». Actes de les Primeres Jornades C atalanes de Soci ologia. Barcelona: Institut d'Estudis $C$ atalans.

Carrasquer, P.; N o guera, J.A.; Varella, R. (1996). El empleo femenino en el sector financiero en España. Barcelona: C olumna-C O N C .

CarRasQ Uer, P.; T ORN S, T . (1983). «M ujer y Trabajo». Crónica de Información Labo ral, núm. 12.

Carrasquer, P.; Torns, T.; Tejero, E.; Romero, A. (1998). «El trabajo reproductivo». Papers, núm. 55.

Chabaud-Rychter, D .; Fougeyrollas-Sch webel, D .; Soutonnax, F. (1985). Espa ce et temps du travail domestique. París: Librairie des M éridiens.

COCKBURN, C. (1991). In the way of women. Londres: M acmillan.

- (1983). Brothers: M aledominance and Thecnological C hange. Londres: Pluto Press.

D AUNE-RICH ARD, A.M . (1986). «D e la construction d'un objet "travail des femmes" a une reconceptualisation du travail». Comunicació presentada al col.loqui Work and Politics. the feminitation of delabor force $\mathrm{H}$ arvard University.

D ELPHY, C . (1987). «M odo de producción doméstico y feminismo materialista». Am oRó S, C. (comp.) M ujeres: Ciencia y práctica política. M adrid: D ebate.

Dex, S. (1988). Women's Attitudes towards Work. Londres: M cM illan.

- (1991). La división sexual del trabajo. M adrid: M inisterio de T rabajo y Seguridad Social.

DURAN, M .A. (1987). La jornada interminable. Barcelona: I caria.

DURAN, M .A. (dir.) (1988). D e puertas adentro. M adrid: Instituto de la M ujer.

FougEYROLLAS-SCH WEBEL, D. (1995). «Le Travail domestique: économie des servitudes et du partage». A H IRATA, H .; Sen OTIER, D. Femmes et partage de travail. París: Syros.

Gardiner, J.; H ARRISSO N , J.; Seccom Be, W. (1975). El ama de casa bajo el capitalis mo. Barcelona: Anagrama.

H ART M AN N, H . (1981). «T he family as the locus of gender, class and political struggle: the exemple of H ousework». Signs, vol. 6, núm. 3.

- (1976). «Patriarchy, capitalism and job segregation by sex». Signs, vol. 1, núm. 3. 
H U M PH RIES, J.; RUBERY, J. (1994). «La autonomía relativa de la reproducción social: su relación con el sistema de producción». A Borderías, CaRRASCO, ALEM ANY, Las mujeres y el trabajo.

LEWIS, J. (1988). «The debate on sex and class». N ew Left Review, núm. 149.

M ACKINTOSH, M . (1986). «D omestic Labour and the H ousehold». A PAHL. On Work.

M aruan I, M.; N ICole, C. (1989). Au labeur des dames. M étiers masculins, emplois féminins. París: Syros.

M eulders, D.; Plasm an n, R.; VAn Der, V. (1993). Position of Women on the Labour $M$ arket in the European Comumnity. Aldershot: Gower.

M eULDERS, D .; PLASM AN N, R. (1994). Atypical Employement in the EC., Aldershot: Gower.

M OLYNEUX, M. (1979). «Beyond the domestic labour debate». N ew Left Review, núm. 116.

PAH L, R.E. (1983). «Strategie del lavoro domestico ed economia informale». Inchies ta, gener-juny.

- (1986). On Work. O xford: Blackwell.

- (1990). «D el'"economia formal" a "formes de treball": models i tendències transnacionals». Papers, núm. 34, Barcelona.

PICCHIO, A. (1994). «El trabajo de la reproducción, tema central en el análisis del mercado laboral». A Bord ERÍAs, CARRASCO, Alem ANY, Las mujeresy el trabajo.

RuBeRY, J. (1997). «W hat do women want fron full employment?». A PHILPOTT, J. Working for full employment. Londres: Routledge.

SARACEN O, C. (1985). Il lavoro mal diviso. Bari: De D onato.

TORNS, T.; CARRASQ UER, P.; Rom ERO, A. (1995). El perfil socio-laboral del paro feme nino en España. M adrid: Instituto de la M ujer.

T o Rns, T. (1997). «Chômage et tolérance sociale à l'exclusion». Les Cahiers du M age, núm. 3-4: 47-56.

T o Rns, T. i altres (1996). L'assetjament sexual en el món del treball a Catalunya. Bellaterra, Informe d'investigació.

Torns, T.; CARRASQ UER, P. (1987). «Entorn dels conceptes de dona i treball». AA.D D. Visió de C atalunya. Barcelona: D iputació de Barcelona. (Versió revisada del text que les autores varen presentar a les II Jornades del Patriarcat, sota el títol D ona i Treball a Catalunya, publicades pel Seminari d'E studis de la D ona-ICE, I'any 1983.)

W ALBY, S. (1986). Patriarchy at work. Cambridge: Polity Press. 